\title{
Pulmonary mucoepidermoid carcinoma arising in a patient with Kartagener syndrome
}

\author{
Yoshiaki Nagai ${ }^{1}$, Nobuyuki Koyama ${ }^{2 *} \mathbb{D}$, Yuki Iwai $^{3}$, Hiroyoshi Tsubochi ${ }^{4}$, Masahiro Hiruta ${ }^{5}$, Yoshiko Mizushina ${ }^{6}$, \\ Shinichiro Koyama ${ }^{6}$, Yuichi Ishikawa ${ }^{7}$ and Koichi Hagiwara ${ }^{1}$
}

\begin{abstract}
Background: Kartagener syndrome, an autosomal recessive disorder with a triad of chronic sinusitis, bronchiectasis, and situs inversus, is characterized by recurrent respiratory tract infections and chronic inflammation of the lung. Information on comorbidities other than infections in patients with Kartagener syndrome is currently limited.

Case presentation: A 39-year-old, non-smoking female was diagnosed with Kartagener syndrome and admitted to Saitama Medical Center, Jichi Medical University, Japan. Computed tomography revealed an endobronchial massive shadow at the ostial site of the right upper lobe bronchus with atelectasis of the right upper lobe. The mass was surgically resected and pathologically diagnosed as mucoepidermoid carcinoma. The lesion had no vascular invasions and no metastases to the lungs or lymph nodes. The surgical margin was negative for carcinoma. Following surgery, the patient has been in good condition.

Conclusions: The present case showed different clinicopathological characteristics from those previously reported in cases of Kartagener syndrome complicated by carcinoma. To the best of our knowledge, this is the first reported case of a young, non-smoking female with comorbid Kartagener syndrome and pulmonary mucoepidermoid carcinoma. This case report may provide a new perspective on the complications of Kartagener syndrome.
\end{abstract}

Keywords: Kartagener syndrome, Mucoepidermoid carcinoma, Atelectasis, Female, Non-smoker

\section{Background}

Kartagener syndrome is an autosomal recessive disorder with a triad of chronic sinusitis, bronchiectasis, and situs inversus [1]. Although the estimated incidence is low (1/ $30000-1 / 60000$ births) [2], fewer patients reach a definitive diagnosis due to an inadequate diagnostic strategy. This disease is characterized by recurrent respiratory tract infections and chronic inflammation of the lung due to congenital ciliary dyskinesia and impaired mucociliary clearance, associated with bronchiectasis and

\footnotetext{
* Correspondence: nkoyama@tokyo-med.ac.jp

2Department of Clinical Oncology, Tokyo Medical University Ibaraki Medical Center, Ibaraki 300-0395, Japan

Full list of author information is available at the end of the article
}

chronic respiratory failure [3, 4]. Radical treatment for Kartagener syndrome has not been established, and therapeutic strategies have been primarily focused on the control of infection. Currently, information on comorbidities other than infections in patients with Kartagener syndrome is limited.

This article presents a young, non-smoking female with Kartagener syndrome complicated by lung cancer. Histologically, the lung cancer arising from the right upper lobe bronchus was a mucoepidermoid carcinoma, a rare type of neoplasm accounting for $0.1-0.2 \%$ of all lung tumors [5]. Pulmonary mucoepidermoid carcinoma is characterized by low-grade malignancy, development from the salivary glands of the proximal

(c) The Author(s). 2020 Open Access This article is licensed under a Creative Commons Attribution 4.0 International License, which permits use, sharing, adaptation, distribution and reproduction in any medium or format, as long as you give appropriate credit to the original author(s) and the source, provide a link to the Creative Commons licence, and indicate if changes were made. The images or other third party material in this article are included in the article's Creative Commons licence, unless indicated otherwise in a credit line to the material. If material is not included in the article's Creative Commons licence and your intended use is not permitted by statutory regulation or exceeds the permitted use, you will need to obtain permission directly from the copyright holder. To view a copy of this licence, visit http://creativecommons.org/licenses/by/4.0/ The Creative Commons Public Domain Dedication waiver (http://creativecommons.org/publicdomain/zero/1.0/) applies to the data made available in this article, unless otherwise stated in a credit line to the data. 
tracheobronchial tree, and the $\mathrm{t}(11 ; 19)$ chromosomal translocation generating a CREB-regulated transcription coactivator 1-mastermind-like 2 (CRTC1-MAML2) fusion oncogene $[6,7]$. The association between Kartagener syndrome and lung cancer has rarely been reported. Previous reports presented six patients with Kartagener syndrome and lung cancer [8-13]. Of those, four patients had squamous cell carcinoma, one patient had small cell carcinoma, and one patient had bronchogenic carcinoma. All patients were male, aged $>50$ years, and heavy smokers.

Thus far, there are no reports showing the history of mucoepidermoid carcinoma. The patient presented in this report had different clinicopathological characteristics from those previously reported, and may provide a novel perspective on Kartagener syndrome.

\section{Case presentation}

A 39-year-old female non-smoker was admitted to Saitama Medical Center, Jichi Medical University, Japan and received continuous care for Kartagener syndrome. The patient was previously admitted to a hospital for productive cough, yellow sputum, and nasal congestion. Chest computed tomography showed bronchiectasis and nodular shadows in both lungs, in addition to situs inversus.

The family history of the patient included nasal disorder (eldest brother) and situs inversus (second elder brother expired at 24 days old). The parents of the patient were cousins. Biopsy of the patient's mucosa in the nasal cavity was performed in the otorhinolaryngology department. Based on the pathological findings, family history, and a triad of chronic sinusitis, bronchiectasis, and situs inversus, the physicians reached the diagnosis of Kartagener syndrome. Moreover, the patient had been diagnosed with chronic obstructive pulmonary disease, and had received treatment with macrolide antibiotics, inhaled corticosteroids/long-acting $\beta 2$ agonists, and tiotropium.

Chest X-ray examination performed in our hospital showed an infiltrative shadow in the right upper lung field suggesting atelectasis of the right upper lobe and tram lines with nodular shadows in both lung fields (Fig. 1). The computed tomography images revealed an endobronchial massive shadow at the ostial site of the right upper lobe bronchus and atelectasis of the right upper lobe (Fig. 2). Bronchoscopic examination identified an obstructing mass at the orifice of the upper lobular bronchus (Fig. 3). Although biopsy failed to achieve a definitive diagnosis, the mass was surgically resected because neoplastic disease was suspected and airway obstruction required surgical intervention. The parts of the right lung chronically infected with Pseudomonas aeruginosa were

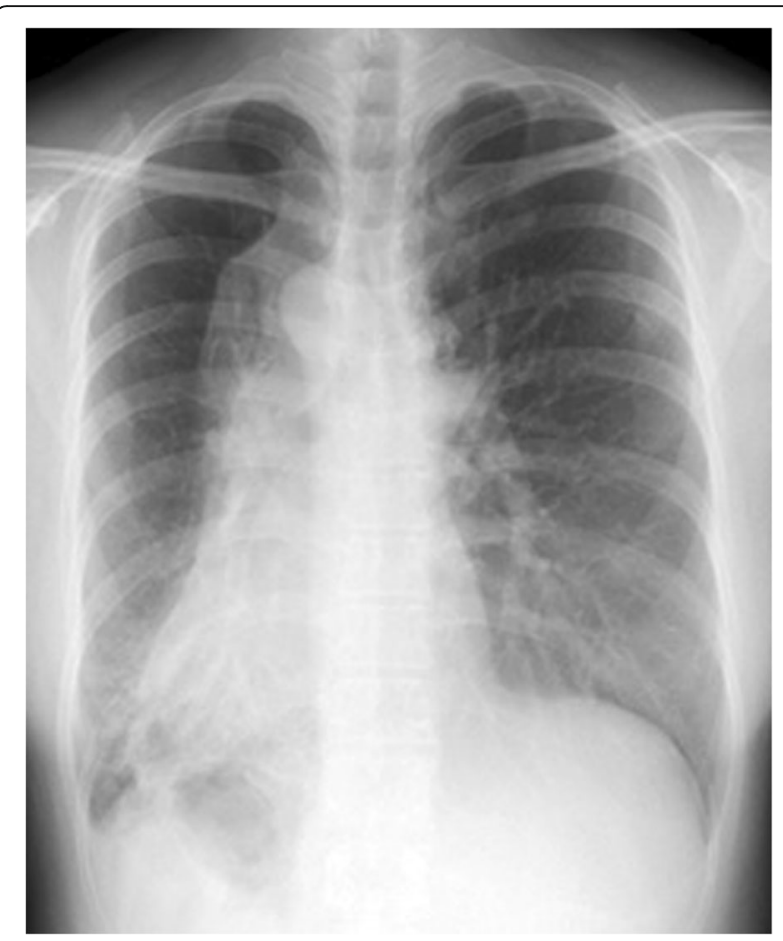

Fig. 1 Chest X-ray examination performed on admission. Chest X-ray image showing an infiltrative shadow in the right upper lung field suggesting atelectasis of the right upper lobe and tram lines with nodular shadows in both lung fields

concomitantly resected. Surgery included the resection of the right upper lobe and the right lower lobe with a preserved right S6 region through anastomosis between the right $\mathrm{B} 6$ and the right main bronchus due to situs inversus. In the resected lung, an opalescent tumor was observed at the right bronchus (Fig. 4a). Microscopically, the tissue specimen revealed a polypoid tumor infiltrating into the bronchial cartilage at low-magnification (Fig. 4b). Histopathological analysis of the tumor provided evidence of mucoepidermoid carcinoma (Figs. 4c, d). Common driver oncogenes and biomarkers in the tumor were negative for mutations in the gene encoding epidermal growth factor receptor $(E G F R) / \nu$-raf murine sarcoma viral oncogene homolog B1 (BRAF) or rearrangements in the anaplastic lymphoma kinase (ALK)/c-ros oncogene 1 (ROS1)/rearranged during transfection proto-oncogene (RET) genes, or the expression of programmed death ligand (PD-L1). The CRTC1-MAML2 gene fusion was not analyzed in this case. The carcinoma arising from a bronchial gland was $1.6 \mathrm{~cm} \times 1.4 \mathrm{~cm}$ in size and invaded into the bronchial cartilage; however, it did not extend outside the bronchus. There was no vascular invasions or metastases to the lungs or lymph nodes. The surgical margin was negative for carcinoma. The right lower lobe showed histopathological findings 


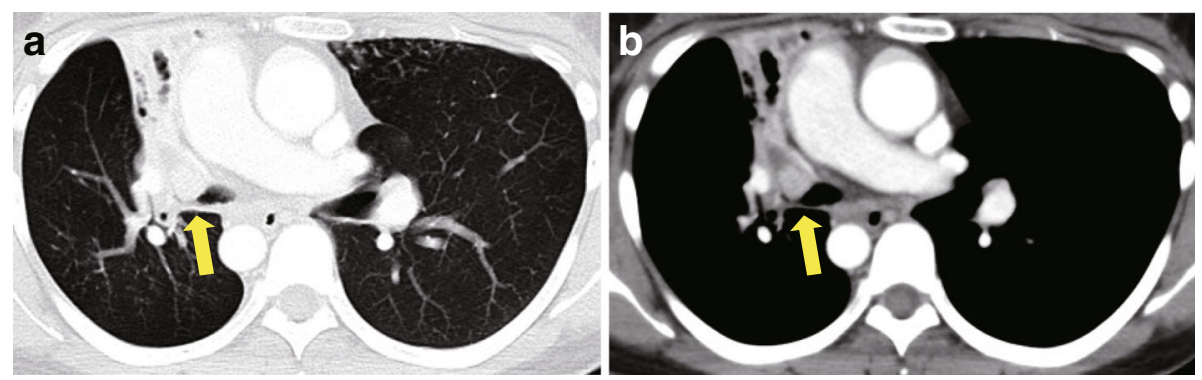

Fig. 2 Chest computed tomography images. Chest computed tomography scan revealing an endobronchial massive shadow at the ostial site of the right upper lobe bronchus associated with atelectasis of the right upper lobe (indicated by arrows)

consistent with Kartagener syndrome (e.g., included alveolar wall thickening, organizing pneumonia with inflammatory cell invasion, bronchiectasis, and enlarged alveolar spaces). Following surgery, the patient has been free of relapse with a decreased incidence of pneumonia.

\section{Discussion and conclusions}

This report presents a case of Kartagener syndrome in a young, non-smoking female complicated by mucoepidermoid carcinoma, a rare histological subtype of lung cancer. To the best of our knowledge, this is the first reported case of a young, non-smoking female with comorbid Kartagener syndrome and lung cancer. The onset of Kartagener syndrome, an autosomal recessive disease, is not associated with age, sex, or history of smoking. In contrast, lung cancer occurs more frequently in the elderly, males, and smokers. Papi et al.

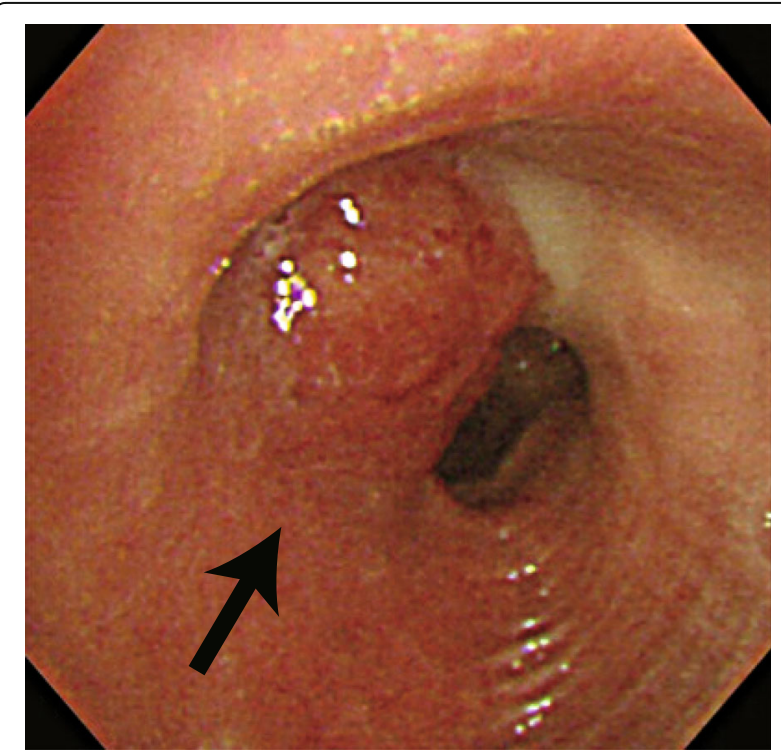

Fig. 3 Bronchoscopic images. Bronchoscopy identified a mass in the upper lobular bronchus with obstruction of its peripheral airway (indicated by an arrow) reported that chronic inflammation due to emphysema and smoking increased the risk of pulmonary squamous cell carcinoma [14]. In previous reports, most patients with Kartagener syndrome who developed lung cancer were smoking males [8-13]. However, mucoepidermoid carcinoma commonly originating from salivary glands exhibits different clinical features from other lung cancers. In the present case, the tumor did not harbor driver oncogenes including, EGFR mutations, which are frequently found in non-smoking females with nonsmall cell lung cancer. Previous case reports have suggested the possible role of congenital lung malformation in the onset of mucoepidermoid carcinoma $[15,16]$. Thus, the histological subtype of mucoepidermoid carcinoma may be etiologically associated with Kartagener syndrome, congenital ciliary dyskinesia, although the biological mechanism remains unknown.

Kartagener syndrome associated with recurrent respiratory tract infections and bronchiectasis is pathophysiologically characterized by chronic inflammation of the lungs. Some researchers reviewed the association of chronic inflammation with tumorigenesis [17, 18]. Chung et al. reported an increased risk of lung cancer in patients with bronchiectasis, one of the clinical phenotypes of Kartagener syndrome [19]. In this context, the pathophysiological process of Kartagener syndrome may have an impact on the onset of mucoepidermoid carcinoma. However, Kim et al. showed inverse comorbidity relationships between lung cancer and chronic inflammation caused by bronchiectasis [20, 21]. Furthermore, Mak et al. reported that patients with bronchiectasis have high levels of transforming growth factor $\beta 1$ in the serum, a potential protective factor against carcinogenesis [22]. Li et al. also reported low incidence of comorbid lung cancer in patients with cystic fibrosis characterized by bronchiectasis [23]. The role of the pathophysiological process of Kartagener syndrome in the risk of developing carcinoma is controversial.

In the context of the pathogenesis of lung cancer in patients with Kartagener syndrome, the different clinicopathological characteristics of the patient in the present 

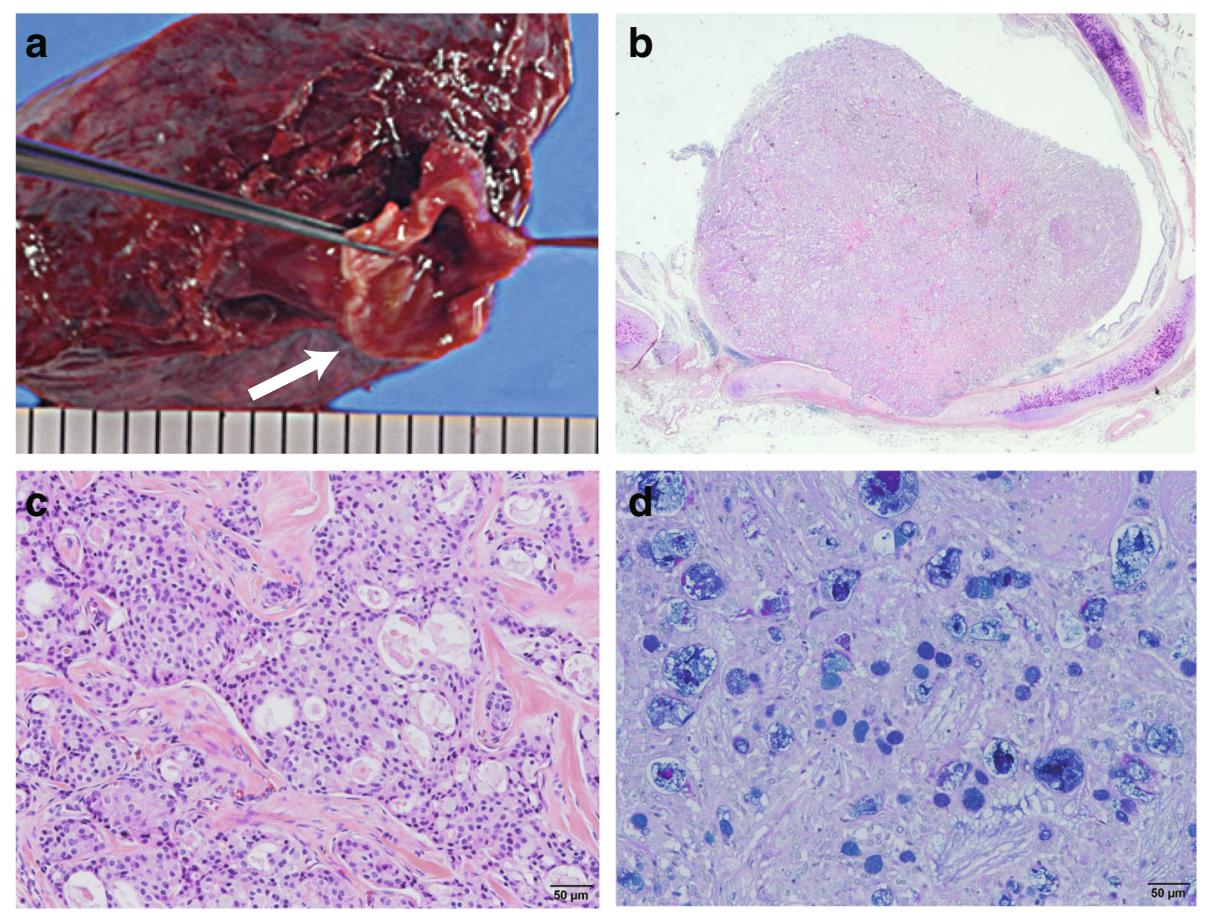

Fig. 4 Pathological findings of the resected tumor. a: An opalescent tumor at the right bronchus was identified at the macroscopic scale (indicated by an arrow). b: A polypoid tumor successively arising from bronchial glands infiltrated into the bronchial cartilage without extrabronchial spread (hematoxylin and eosin staining, 5x). c, d: Mucoepidermoid carcinoma with mixed mucus-producing and squamous epithelia proliferated in a glandular-forming manner (c hematoxylin and eosin staining, 100x; $\mathbf{d}$ Alcian blue-periodic acid-Schiff staining, 100x)

report from those reported in previous cases suggest that different mechanisms may develop malignancy of the lung in patients with Kartagener syndrome [13]. A case series analysis is warranted to determine whether mucoepidermoid carcinoma is causally associated with Kartagener syndrome.

In conclusion, this article presents the first reported case of pulmonary mucoepidermoid carcinoma developed in a patient with unusual characteristics for lung neoplasms such as young age, female sex, no history of smoking, and presence of Kartagener syndrome. These findings emphasize the need for caution following the onset of malignancy as a complication in patients with Kartagener syndrome and unusual clinicopathological characteristics.

\section{Abbreviations}

ALK: Anaplastic lymphoma kinase; BRAF: V-raf murine sarcoma viral oncogene homolog B1; CRTC1-MAML2: CREB-regulated transcription coactivator 1-mastermind-like 2; EGFR: Epidermal growth factor receptor; PDL1: Programmed death ligand; RET: Rearranged during transfection protooncogene; ROS1: C-ros oncogene 1

\section{Acknowledgements}

Not applicable.

\section{Authors' contributions}

YN and NK made substantial contributions to the conception and design acquisition of data, or analysis and interpretation of data. YN and NK were involved in drafting the manuscript. Yl generated images. HT performed the surgical intervention in this case and made the acquisition and interpretation of data on the surgery and the pathology. MH provided pathological images. YI provided suggestions and advice for pathological images and findings. YN, NK, YI, YM, and SK treated the patient. YI, HT, MH, YM, SK, and YI substantively revised the manuscript. $\mathrm{KH}$ was involved in critically revising the manuscript for important intellectual content. All authors read and approved the final version of the manuscript.

\section{Funding}

Funding was not received for this study.

\section{Availability of data and materials}

All data generated during this study are included in this published article.

\section{Ethics approval and consent to participate}

Not applicable.

\section{Consent for publication}

Written informed consent to publish this case report and accompanying data was obtained from the patient.

\section{Competing interests}

All authors declare that they have no competing interests.

\section{Author details}

${ }^{1}$ Department of Respiratory Medicine, Jichi Medical University, Shimotsuke, Japan. ${ }^{2}$ Department of Clinical Oncology, Tokyo Medical University Ibaraki Medical Center, Ibaraki 300-0395, Japan. ${ }^{3}$ Department of Respiratory Medicine, Tokyo Medical University lbaraki Medical Center, Ibaraki, Japan. ${ }^{4}$ Department of Respiratory Surgery, Jichi Medical University Saitama Medical Center, Saitama, Japan. ${ }^{5}$ Department of Pathology, Jichi Medical University Saitama Medical Center, Saitama, Japan. ${ }^{6}$ Department of Respiratory Medicine, Jichi Medical University Saitama Medical Center, Saitama, Japan. ${ }^{7}$ Department of Pathology, Japanese Foundation for Cancer Research, Tokyo, Japan. 
Received: 5 September 2018 Accepted: 3 April 2020

Published online: 16 April 2020

\section{References}

1. Greenstone M, Rutman A, Dewar A, Mackay I, Cole PJ. Primary ciliary dyskinesia: cytological and clinical features. Q J Med. 1988;67(253):405-23.

2. Rott HD. Kartagener's syndrome and the syndrome of immotile cilia. Hum Genet. 1979;46(3):249-61.

3. Afzelius BA. A human syndrome caused by immotile cilia. Science. 1976; 193(4250):317-9.

4. $\quad$ Sleigh MA. Primary ciliary dyskinesia. Lancet. 1981;2(8244):476.

5. Leonardi HK, Jung-Legg Y, Legg MA, Neptune WB. Tracheobronchial mucoepidermoid carcinoma. Clinicopathological features and results of treatment. J Thorac Cardiovasc Surg. 1978;76(4):431-8.

6. Yousem SA, Hochholzer L. Mucoepidermoid tumors of the lung. Cancer. 1987;60(6):1346-52.

7. Behboudi A, Enlund F, Winnes M, Andren Y, Nordkvist A, Leivo I, Flaberg E, Szekely L, Makitie A, Grenman R, et al. Molecular classification of mucoepidermoid carcinomas-prognostic significance of the MECT1-MAML2 fusion oncogene. Genes Chromosomes Cancer. 2006;45(5):470-81.

8. Baruah BD, Chari MV. Kartagener's syndrome with bronchogenic carcinoma. J Indian Med Assoc. 1952;21(10):438-9.

9. Kawanishi M, Matsushima T, Yagi S, Y N, Soejima R. A case report of epidermoid carcinoma of the lung considered recurrent pneumonia in Kartagener's Syndrome. Kawasaki Med J. 1980;6:247-51.

10. Hachiya T, Koizumi T, Hayasaka M, Honda T, Kubo K, Sekiguchi M, Mochizuki I. A case of Kartagener's syndrome with lung Cancer. J Jpn Soc Resp Endoscopy. 1993;15:179-84.

11. Higashi Y, Sanuki K, Agari M, Nasuno Y, Yokoyama T, Gondou T. A case of small cell lung Cancer accompaning SIADH and Kartagener syndrome. Jpn J Chest Dis. 1994:53:45-8.

12. Horie M, Arai H, Noguchi S, Suzuki M, Sakamoto Y, Oka T. Kartagener syndrome with lung cancer and mediastinal tumor. Nihon Kokyuki Gakkai Zasshi. 2010;48(5):375-8.

13. Inoue $Y$, Suga A, Sekido Y, Yamada S, Iwazaki M. A case of surgically resected lung cancer in a patient with Kartagener's syndrome. Tokai J Exp Clin Med. 2011;36(2):21-4.

14. Papi A, Casoni G, Caramori G, Guzzinati I, Boschetto P, Ravenna F, Calia N, Petruzzelli S, Corbetta L, Cavallesco G, et al. COPD increases the risk of squamous histological subtype in smokers who develop non-small cell lung carcinoma. Thorax. 2004;59(8):679-81.

15. Pandya $\mathrm{H}$, Matthews $\mathrm{S}$. Case report: Mucoepidermoid carcinoma in a patient with congenital agenesis of the left upper lobe. Br J Radiol. 2003; 76(905):339-42.

16. Harini N, Chakravarthy R, Archana L. Congenital pulmonary airway malformation with mucoepidermoid carcinoma: a case report and review of literature. Indian J Pathol Microbiol. 2012;55(4):540-2.

17. Vakkila J, Lotze MT. Inflammation and necrosis promote tumour growth. Nat Rev Immunol. 2004;4(8):641-8.

18. Raviv S, Hawkins KA, DeCamp MM Jr, Kalhan R. Lung cancer in chronic obstructive pulmonary disease: enhancing surgical options and outcomes. Am J Respir Crit Care Med. 2011;183(9):1138-46.

19. Chung WS, Lin $\mathrm{CL}, \mathrm{Hsu}$ WH, Kao CH. Increased risk of lung cancer among patients with bronchiectasis: a nationwide cohort study. QJM. 2016;109(1):17-25.

20. Kim YW, Jin KN, Heo EY, Park SS, Chung HS, Kim DK. The association between combined non-cystic fibrosis bronchiectasis and lung cancer in patients with chronic obstructive lung disease. Int J Chron Obstruct Pulmon Dis. 2015;10:873-9.

21. Kim YW, Lee $\mathrm{CH}$, Jin KN, Lee JK, Heo EY, Park SS, Chung HS, Kim DK. The regional association between bronchiectasis and lung cancer in chest $\mathrm{CT}$. BMC Pulm Med. 2016:16(1):151.

22. Mak JC, Ho SP, Leung RY, Ho PL, Ooi C, Tipoe GL, Yan C, Ip MS, Lam WK, Tsang KW. Elevated levels of transforming growth factor-beta (1) in serum of patients with stable bronchiectasis. Respir Med. 2005;99(10):1223-8.

23. Li Y, Sun Z, Wu Y, Babovic-Vuksanovic D, Li Y, Cunningham JM, Pankratz VS, Yang P. Cystic fibrosis transmembrane conductance regulator gene mutation and lung cancer risk. Lung Cancer. 2010;70(1):14-21.

\section{Publisher's Note}

Springer Nature remains neutral with regard to jurisdictional claims in published maps and institutional affiliations.

Ready to submit your research? Choose BMC and benefit from:

- fast, convenient online submission

- thorough peer review by experienced researchers in your field

- rapid publication on acceptance

- support for research data, including large and complex data types

- gold Open Access which fosters wider collaboration and increased citations

- maximum visibility for your research: over $100 \mathrm{M}$ website views per year

At $\mathrm{BMC}$, research is always in progress.

Learn more biomedcentral.com/submissions 